AbbVie, MSD, Novartis and Pfizer, Consultant of: AbbVie, MSD, Novartis and Pfizer

DOI: 10.1136/annrheumdis-2020-eular.3036

\section{FRI0339 LONG-TERM EFFICACY OF THE ORAL SELECTIVE JANUS KINASE 1 INHIBITOR FILGOTINIB IN PSORIATIC ARTHRITIS: WEEK 52 RESPONSE PATTERNS IN INDIVIDUAL PATIENTS FROM AN OPEN-LABEL EXTENSION (OLE) STUDY (EQUATOR2)}

D. D. Gladman ${ }^{1}$, L. C. Coates ${ }^{2}$, F. Van den Bosch ${ }^{3}$, P. Helliwell ${ }^{4}$, C. Tasset ${ }^{5}$, L. Meuleners ${ }^{5}$, L. Gilles ${ }^{6}$, L. Gheyle ${ }^{5}$, M. Trivedi ${ }^{7}$, M. Alani ${ }^{7,8}$, R. Besuyen ${ }^{9}$, P. J. Mease ${ }^{8,10}$. ${ }^{1}$ University of Toronto, Toronto, United States of America; ${ }^{2}$ Botnar Research Centre, University of Oxford, Oxford, United Kingdom; ${ }^{3}$ Ghent University Hospital, Ghent, Belgium; ${ }^{4}$ University of Leeds, Leeds, United Kingdom; ${ }^{5}$ Galapagos NV, Mechelen, Belgium; ${ }^{6}$ LACO, contracted by Galapagos NV, Mechelen, Belgium; ${ }^{7}$ Gilead Sciences, Inc, Foster City, CA, United States of America; ${ }^{8}$ University of Washington, Seattle, United States of America; ${ }^{9}$ Galapagos BV, Leiden, Netherlands; ${ }^{10}$ Swedish Medical Centre, Seattle, United States of America

Background: EQUATOR (NCT03101670) was a 16-week, Phase 2, multicenter double-blind, placebo-controlled, randomized controlled trial (RCT) of filgotinib in patients with active psoriatic arthritis. ${ }^{1}$ Filgotinib demonstrated rapid efficacy compared with placebo across multiple domains, including the primary endpoint of Week 16 American College of Rheumatology (ACR) 20 response. Patients completing the RCT could join an ongoing 148-week OLE (EQUATOR2; NCT03320876).

Objectives: In this prespecified interim analysis at Week 52 of the OLE, individual patient responses with respect to disease activity were evaluated

Methods: Placebo-treated RCT patients switched to filgotinib (200 mg once daily) at Week 16 and entered the OLE; patients previously assigned to filgotinib continued. Individual response patterns at Week 52 of the OLE were evaluated for ACR20/50/70, Psoriatic Arthritis Disease Activity Score (PASDAS) low disease activity (LDA), minimal disease activity (MDA), and MDA/very low disease activity (VLDA)

Results: 124 patients (95\%) completed EQUATOR; 122 (93\%) enrolled in the OLE. At Week 52, 11 patients (9\%) had discontinued treatment in the OLE. Median (range) exposure to filgotinib was $66.0(0.4-104.1)$ weeks. In patients originally assigned to filgotinib, sustained efficacy was seen through to OLE Week 52 for ACR20, 50, and 70; PASDAS LDA; MDA (Table; Figure 1a); and MDA/VLDA. In total, $77 \%$ and $93 \%$ of those achieving MDA and ACR50 response in the RCT period maintained this at Week 52 (Table). A substantial proportion of RCT non-responders also achieved a treatment response in the OLE, meeting MDA and ACR50 criteria (22\% and $37 \%$, respectively; Table). Response patterns in the OLE were similar regardless of prior RCT treatment. In total, at Week 52 of the OLE, $33.6 \%$ of patients achieved MDA response (Figure 1a); $55.0 \%$ achieved ACR50 response. Figure $1 \mathrm{~b}$ shows individual patient response over time for MDA.

Conclusion: Data from this 52-week OLE interim analysis suggest that further improvement in disease activity can be expected with filgotinib beyond 16 weeks in patients with active psoriatic arthritis. Sustained efficacy was demonstrated across several measures of disease activity, including MDA and ACR50.

References:

[1] Mease P, et al. Lancet 2018;392:2367-77.

Table. Responders at Week 52 of the OLE, by treatment and previous RCT responder status (observed cases).

\begin{tabular}{|c|c|c|c|c|}
\hline \multirow{2}{*}{$\begin{array}{l}\text { Treatment } \\
\mathrm{n} / \mathrm{N}, \%\end{array}$} & \multicolumn{2}{|c|}{$\begin{array}{c}\text { Filgotinib } \\
(\mathrm{N}=59) \rightarrow \text { Filgotinib }(\mathrm{N}=54)^{\mathrm{a}}\end{array}$} & \multicolumn{2}{|c|}{$\begin{array}{c}\text { Placebo } \\
(\mathrm{N}=63) \rightarrow{\text { Filgotinib }(\mathrm{N}=57)^{\mathrm{a}}}\end{array}$} \\
\hline & $\begin{array}{l}\text { OLE responders/ } \\
\text { RCT responders }\end{array}$ & $\begin{array}{c}\text { OLE } \\
\text { responders/RCT } \\
\text { non-responders }\end{array}$ & $\begin{array}{l}\text { OLE responders/ } \\
\text { RCT responders }\end{array}$ & $\begin{array}{c}\text { OLE } \\
\text { responders/RCT } \\
\text { non-responders }\end{array}$ \\
\hline ACR20 & $40 / 47(85.1)$ & $5 / 7$ (71.4) & $17 / 18$ (94.4) & $27 / 38(71.1)$ \\
\hline ACR50 & $25 / 27(92.6)$ & $10 / 27(37.0)$ & $5 / 8(62.5)$ & $21 / 49$ (42.9) \\
\hline ACR70 & $10 / 13$ (76.9) & $12 / 41(29.3)$ & $3 / 4(75.0)$ & $12 / 53(22.6)$ \\
\hline $\begin{array}{l}\text { PASDAS } \\
\text { LDA }^{\mathrm{b}}\end{array}$ & $19 / 21(90.5)$ & $12 / 32(37.5)$ & $5 / 6(83.3)$ & $21 / 48(43.8)$ \\
\hline MDA & $10 / 13(76.9)$ & $9 / 41(22.0)$ & $4 / 5(80.0)$ & $14 / 51$ \\
\hline
\end{tabular}

andicates number remaining at OLE Week 52 interim analysis, after dropouts

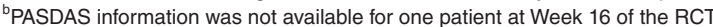

Figure 1. Patients achieving ACR50 and MDA over time (a) and MDA per patient over time (b).

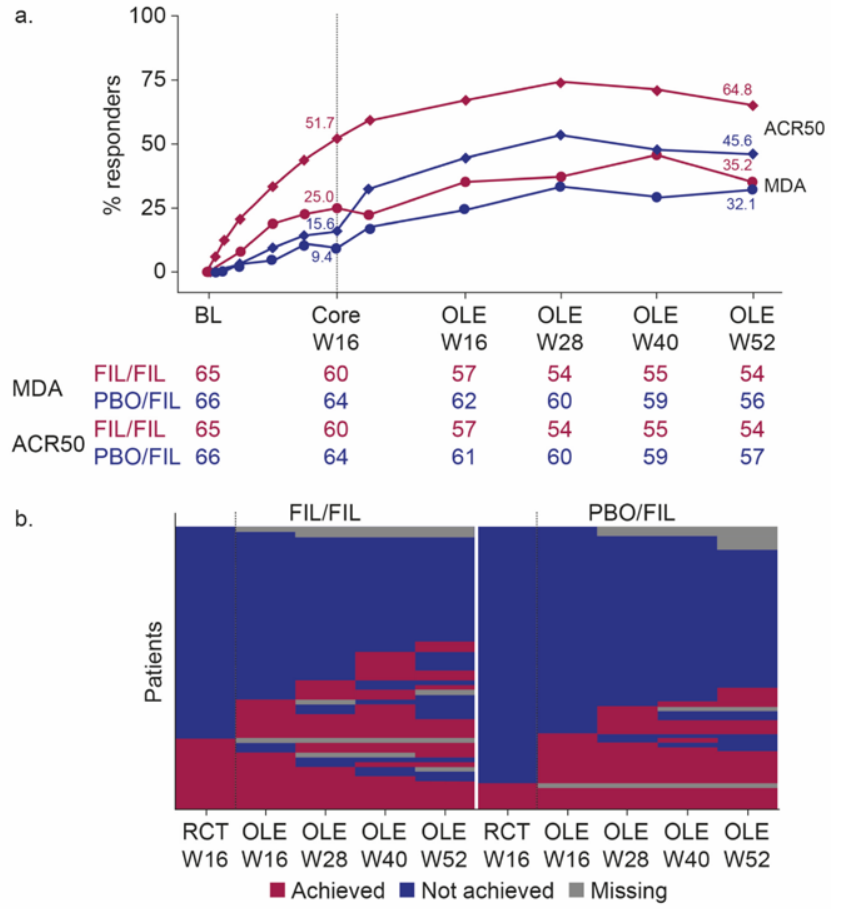

Acknowledgments: EQUATOR and EQUATOR2 were sponsored by Galapagos NV and co-funded by Galapagos NV and Gilead Sciences. Medical writing support was provided by Hannah Mace MPharmacol, CMPP (Aspire Scientific Ltd, Bollington, UK) and funded by Galapagos NV.

Disclosure of Interests: Dafna D Gladman Grant/research support from: AbbVie, Amgen Inc., BMS, Celgene Corporation, Janssen, Novartis, Pfizer, UCB - grant research support, Consultant of: AbbVie, Amgen Inc., BMS, Celgene Corporation, Janssen, Novartis, Pfizer, UCB - consultant, Laura C Coates: None declared, Filip van den Bosch Consultant of: AbbVie, Celgene Corporation, Eli Lilly, Galapagos Janssen, Novartis, Pfizer, and UCB, Speakers bureau: AbbVie, Celgene Corporation, Eli Lilly, Galapagos, Janssen, Novartis, Pfizer, and UCB, Philip Helliwell: None declared, Chantal Tasset Shareholder of: Galapagos (share/warrant holder), Employee of: Galapagos, Luc Meuleners Employee of: Galapagos, Leen Gilles Consultant of: Galapagos, Lien Gheyle Employee of: Galapagos, Mona Trivedi Shareholder of: Amgen and Gilead Sciences, Employee of: Gilead Sciences, Muhsen Alani Employee of: Gilead Sciences, Robin Besuyen Shareholder of Galapagos, Employee of: Galapagos, Philip J Mease Grant/research support from: Abbott, Amgen, Biogen Idec, BMS, Celgene Corporation, Eli Lilly, Novartis Pfizer, Sun Pharmaceutical, UCB - grant/research support, Consultant of: Abbott, Amgen, Biogen Idec, BMS, Celgene Corporation, Eli Lilly, Novartis, Pfizer, Sun Pharmaceutical, UCB - consultant, Speakers bureau: Abbott, Amgen, Biogen Idec, BMS, Eli Lilly, Genentech, Janssen, Pfizer, UCB - speakers bureau DOI: 10.1136/annrheumdis-2020-eular.2624

\section{FRI0340 COMPARISON OF SECUKINUMAB VERSUS ADALIMUMAB EFFICACY ON SKIN OUTCOMES IN PSORIATIC ARTHRITIS: 52-WEEK RESULTS FROM THE EXCEED STUDY}

A. B. Gottlieb ${ }^{1}$, F. Behrens ${ }^{2}$, P. Nash ${ }^{3}$, J. F. Merola ${ }^{4}$, K. Ding ${ }^{5}$, P. Pellet ${ }^{6}$, L. Pricop ${ }^{5}$, I. Mcinnes ${ }^{7}{ }^{1}$ Icahn School of Medicine at Mount Sinai, New York, United States of America; ${ }^{2}$ Rheumatology University Hospital and Goethe University, Frankfurt, Germany; ${ }^{3}$ Griffith University, Brisbane, Australia; ${ }^{4}$ Brigham and Women's Hospital, Harvard Medical School, Boston, United States of America; ${ }^{5}$ Novartis Pharmaceuticals Corporation, East Hanover, United States of America; ${ }^{6}$ Novartis Pharma AG, Basel, Switzerland; ' University of Glasgow, Glasgow, United Kingdom

Background: Psoriatic arthritis (PsA) is a heterogeneous disease comprising musculoskeletal and dermatological manifestations, especially plaque psoriasis. ${ }^{1}$ Secukinumab (SEC), an IL-17A inhibitor, provided significantly greater PASI 75/100 responses in a head-to-head trial versus (vs.) etanercept, a TNF inhibitor, in patients (pts) with moderate-to-severe plaque psoriasis. ${ }^{2}$ The objective of the EXCEED study (NCT02745080) was to investigate whether SEC is superior to 
adalimumab (ADA), a TNF inhibitor, as monotherapy in biologic-naive active PsA pts with active plaque psoriasis (defined as having at least one psoriatic plaque of $\geq 2 \mathrm{~cm}$ diameter or nail changes consistent with psoriasis or documented history of plaque psoriasis).

Objectives: To report the pre-specified skin outcomes from the EXCEED study in the subset of pts with at least $3 \%$ body surface area (BSA) affected with psoriasis at baseline.

Methods: Head-to-head, phase-3b, randomised, double-blind, active-controlled, multicentre, parallel-group trial: pts were randomised to receive SEC $300 \mathrm{mg}$ subcutaneous at baseline, Week 1-4, followed by dosing every 4 weeks (q4w) until Week 48 or ADA $40 \mathrm{mg}$ subcutaneous at baseline followed by same dosing q2w until Week 50 . The primary endpoint was superiority of SEC vs. ADA on ACR20 response at Week 52. Pre-specified outcomes included the proportion of pts achieving a combined ACR50 and PASI 100 response, PASI 100 response, and absolute PASI score $\leq 3$. Missing data was handled using multiple imputation.

Results: 853 pts were randomised to receive SEC $(n=426)$ or ADA ( $n=427)$. At baseline, there were 215 and 202 pts having at least 3\% BSA affected with psoriasis in the SEC and ADA groups, respectively. A higher proportion of patients achieved simultaneous improvement in ACR50 and PASI 100 response with SEC vs. ADA (30.7\% vs. $19.2 \%$; $P=0.0087$ [Figure]). Higher efficacy was demonstrated for SEC vs. ADA for PASI 100 responses and for the proportion of pts achieving absolute PASI score $\leq 3$ (Table).

Conclusion: In this pre-specified analysis, SEC provided higher responses compared to ADA in achievement of simultaneous improvement of joint and skin disease (combined ACR50 and PASI 100 response) and in skin specific endpoints (PASI 100 and PASI score $\leq 3$ ) at Week 52.

References:

[1] Coates LC and Helliwell PS. Clinical Med.2017;17:65-70.

[2] Langley RG et al. N Engl J Med. 2014;371:326-38.

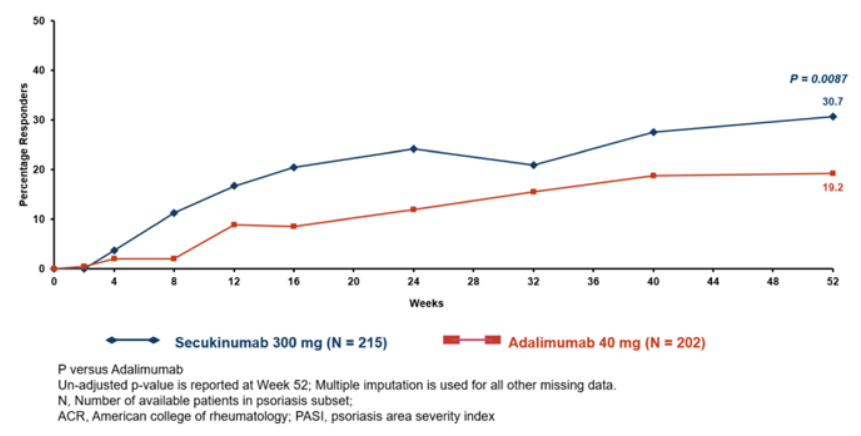

Figure. Combined ACR50 and PASI 100 Response through Week 52

Table. Skin Specific Outcomes at Week 52

Endpoints, data is presented as \% response SEC $300 \mathrm{mg}$ ADA $40 \mathrm{mg}$ P-value (unadjusted) $(\mathrm{N}=215) \quad(\mathrm{N}=202)$

\begin{tabular}{llll}
\hline PASI 100 & 46.0 & 29.7 & 0.0007 \\
Absolute PASI score $\leq 3$ & 79.2 & 65.0 & 0.0015
\end{tabular}

$P$ value vs. adalimumab; Unadjusted $P$ values are presented

$\mathrm{N}$, number of patients in psoriasis subset

Multiple imputation was used for handling missing data

ADA, adalimumab; BSA, body surface area; PASI, psoriasis area severity index; SEC, secukinumab

Acknowledgments: Suchita Dubey (Novartis) provided medical writing support. Disclosure of Interests: Alice B Gottlieb Grant/research support from:: Research grants, consultation fees, or speaker honoraria for lectures from: Pfizer, AbbVie, BMS, Lilly, MSD, Novartis, Roche, Sanofi, Sandoz, Nordic, Celltrion and UCB., Consultant of:: Research grants, consultation fees, or speaker honoraria for lectures from: Pfizer, AbbVie, BMS, Lilly, MSD, Novartis, Roche, Sanofi, Sandoz, Nordic, Celltrion and UCB., Speakers bureau:: Research grants, consultation fees, or speaker honoraria for lectures from: Pfizer, AbbVie, BMS, Lilly, MSD, Novartis, Roche, Sanofi, Sandoz, Nordic, Celltrion and UCB., Frank Behrens Grant/research support from: Pfizer, Janssen, Chugai, Celgene, Lilly and Roche, Consultant of: Pfizer, AbbVie, Sanofi, Lilly, Novartis, Genzyme, Boehringer, Janssen, MSD, Celgene, Roche and Chugai, Peter Nash Grant/research support from: AbbVie, Bristol-Myers Squibb, Celgene, Eli Lilly and Company, Gilead, Janssen, MSD, Novartis, Pfizer Inc, Roche, Sanofi, UCB, Consultant of: AbbVie, Bristol-Myers Squibb, Celgene, Eli Lilly, Gilead, Janssen, MSD, Novartis, Pfizer Inc, Roche, Sanofi, UCB, Speakers bureau: AbbVie, Bristol-Myers Squibb, Celgene, Eli Lilly, Gilead, Janssen, MSD, Novartis, Pfizer Inc, Roche, Sanofi, UCB, Joseph F. Merola Consultant of: Merck, AbbVie, Dermavant, Eli Lilly, Novartis,
Janssen, UCB Pharma, Celgene, Sanofi, Regeneron, Arena, Sun Pharma, Biogen, Pfizer, EMD Sorono, Avotres and LEO Pharma, Kevin Ding Employee of: Novartis, Pascale Pellet Shareholder of: Novartis, Employee of: Novartis, Luminita Pricop Shareholder of: Novartis, Employee of: Novartis, lain Mclnnes Grant/ research support from: Bristol-Myers Squibb, Celgene, Eli Lilly and Company, Janssen, and UCB, Consultant of: AbbVie, Bristol-Myers Squibb, Celgene, Eli Lilly and Company, Gilead, Janssen, Novartis, Pfizer, and UCB DOI: 10.1136/annrheumdis-2020-eular.4736

\section{FRI0341 RISK FACTORS FOR AXIAL INVOLVEMENT IN EARLY PSORIATIC ARTHRITIS}

E. Gubar ${ }^{1}$, E. Loginova ${ }^{1}$, S. Glukhova ${ }^{1}$, T. Korotaeva ${ }^{1} .{ }^{1}$ Nasonova Research Institute of Rheumatology, Moscow, Russian Federation

Background: Axial Involvement in psoriatic arthritis (PsA) is quite common [1] Predictors of axial involvement at early-stage of disease haven't been sufficiently studied.

Objectives: To identify predictors of axial involvement in PsA patients (pts) at early-stage of disease.

Methods: 95 patients (pts) (M/F-47/48) with early PsA fulfilling the CASPAR criteria were included. All pts had peripheral arthritis for $\leq 2$ years; no inflammatory back pain (IBP) pts were specifically selected. Mean (Me) age $36.5 \pm 10.7$ yrs, disease duration $12.2 \pm 10.3 \mathrm{mo}$. Pts underwent standard clinical examination of PsA activity. Me disease activity indexes DAS $=4.0 \pm 1.4$, DAS28=4.2 \pm 1.1 , $\mathrm{BASDAl}=4.5 \pm 1.6$; Me pts global disease activity VAS $56.9 \pm 17.1$. All patients were evaluated for the presence of IBP by ASAS criteria, underwent sacroiliac joints (SIJs) X-ray (pelvic radiographs) and HLA B27 antigen status study. MRI of SIJs was performed in 79 pts, regardless of IBP presence, on Signa Ovation 0.35T. Radiographic sacroiliitis (R-SI) was identified according to New York criteria (unilateral grade $\geq 3$ or bilateral grade $\geq 2$ ). Bone marrow edema/ osteitis on MRI (STIR) was considered active MRI sacroiliitis (MRI-SI). X-ray and MRI results were evaluated by an independent reader. IBP was observed in $63(66.3 \%)$ cases, MRI-SI in 28 of $79(35.4 \%)$ examined cases, R-SI in 29 (30.5\%) cases. Skin lesion severity was evaluated as body surface area (BSA) affected: minor at $<3 \%$, mild at $3-10 \%$, severe at $>10 \%$. Pts were split into 2 groups (gr.): those with axial involvement (axPsA), that is with IBP and/or R-SI and/or MRI-SI; and those without axial involvement (having only peripheral PsA [pPsA]). The axPsA gr. included 65 (68.4\%) cases, the pPsA gr. 30 (31.6\%) cases. Multi-dimensional step-by-step discriminant analysis was used to identify a group of features that are more typical for the axPsA patients.

\section{ROC Curve}

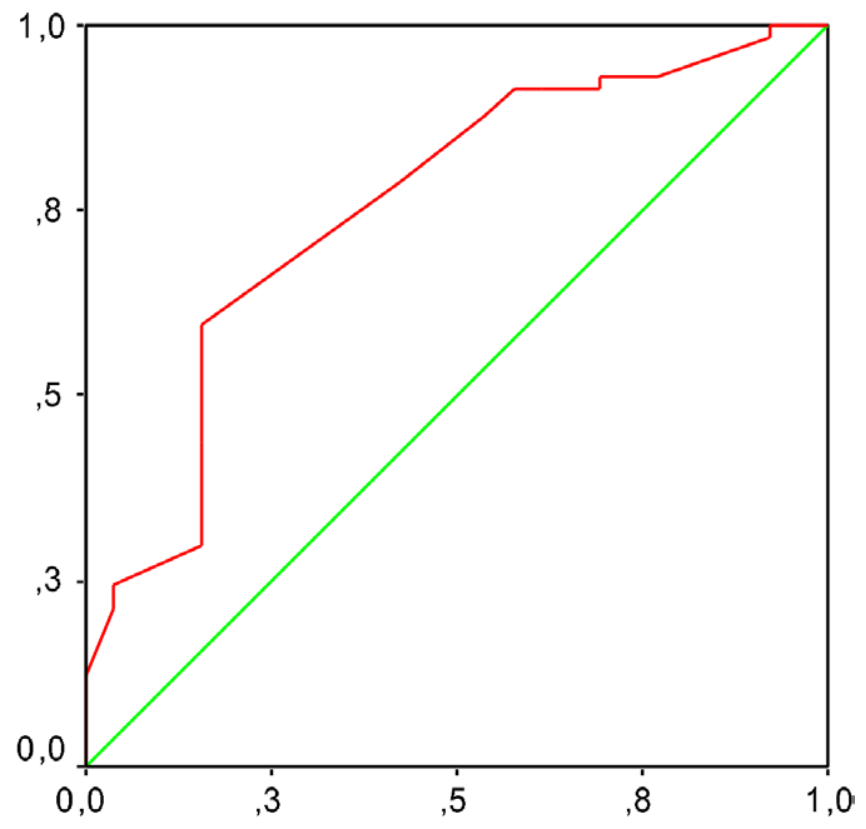

\section{1 - Specificity}

Diagonal segments are produced by ties. 